\title{
One-dimensional compression of a crushable sand in dry and wet conditions
}

\author{
L. Wils, P.O. Van Impe \& W. Haegeman \\ Laboratory of Geotechnics, Ghent University, Belgium
}

\begin{abstract}
This paper presents the results of a series of dry and wet one-dimensional compression tests on a calcareous sand from the Persian Gulf. Calcareous grains crush more easily compared to silica grains, a fact that is mainly attributed to their angular shape and weaker mineralogical constitution and complicates their geotechnical behaviour. With regard to the use of crushable sands in construction projects, the question arises whether the presence of water further influences their crushability, and thus performance. The oedometer tests discussed in this paper, are part of a larger study on the influence of water on the stress-strain behaviour of calcareous sands. Dry samples are prepared in oedometers at a relevant density and either kept dry or flushed with water. Loading occurs in ten increments up until a vertical stress of $8.6 \mathrm{MPa}$ and afterwards the sand is sieved to evaluate crushing. The behaviour of the crushable sand is shown to be significantly affected by the water as soon as crushing is initiated. The total settlements and the crushability are higher for the wet sand. When a distinction is made between primary and secondary compression, it is found that wet sand compresses more than dry sand during consolidation phase, but less during secondary compression phase. As a result, the observed, net differences decrease with longer loading time whereas a higher rate of loading furthers the increased compression of wet calcareous sand. The tests are repeated on Molsand, a non-crushable silica sand. For this sand, within the stress range tested, the net deformation is identical for wet and dry conditions. The elevated stresses were not high enough to crush the grains and yield the material. The water-dependency of crushable sands already exists at moderate stress levels, so it is of great importance to incorporate the accelerated crushing of wet particles in the geotechnical engineering practice.
\end{abstract}

\section{INTRODUCTION}

The angular grain shape, weaker mineralogical constitution, intraparticle porosity and high natural void ratio of calcareous sands of biological origin make for a specific geotechnical behaviour (Datta et al. 1979, Nauroy \& Le Tirant 1982, Semple 1988), which seems rather different and less documented than that of more common non-crushable silica sands. However, much can be learned from the behaviour of silica sand that is subjected to load levels high enough to induce crushing (Hardin 1985, Miura \& Yamanouchi 1975, Coop \& Lee 1993, Hagerty et al. 1993, Pestana \& Whittle 1995, Nakata et al. 2001a, b), and it appears that the soft response of calcareous sand does fit in a general framework for cohesionless soils indeed (Semple 1988, Coop 1990).

There is a general consensus that grain crushing is the principal mechanism regulating the compression behaviour after a certain threshold stress has been reached (Marsal 1967) and that the factors that influence single particle crushing will affect the macroscale compression behaviour (Kwag et al. 1999, Nakata et al. 2001a, b).

Most of the factors that govern a soil's vulnerability to crush, are already quite extensively described in the literature. They are intrinsic material characteristics, namely particle angularity (e.g. Hardin 1985, Hagerty et al. 1993), mineralogy (e.g. Hardin 1985, Hagerty et al. 1993), grain size (e.g. Hagerty et al. 1993, Kwag et al. 1999, Nakata et al. 2001b) and grain size distribution (e.g. Hardin 1985, Nakata et al. 2001a) and test conditions, like packing density (e.g. Hardin 1985, Datta et al. 1982, Semple 1988, Hagerty et al. 1993), stress levels (e.g. Hardin 1985), stress path (e.g. Airey et al. 1988, Lade et al. 1996), loading rate and time (e.g. Poulos et al. 1982, Semple 1988, Coop 1990 , Lade et al. 1997), and water (Miura \& Yamanouchi 1975).

Research on the effect of water on grain interaction is however rather scarce, probably since a difference between wet and dry standard silica sand does not occur under the commonly encountered load levels. The preferential test conditions may then be the outcome of practical considerations. E.g. drained triaxial tests on sand may be favoured to dry triaxial tests, because of the advantage of volume change measurements, and calibration chamber tests on sand are usually done under dry conditions because of the difficulty to saturate such large scale samples.

However, when running isotropic compression tests at high pressures, up to $50 \mathrm{MPa}$, Miura \& Yamanouchi (1975) found that saturated Toyoura sand was more compressible than dry Toyoura sand. This 
was explained from a mechano-chemical viewpoint. Water accelerates the particle-crushing because of its high polarity, low viscosity and small molar volume, thus decreasing the surface energy inside grain cracks which are produced under high stresses.

Ham et al. (2010) performed dry and wet oedometer tests (up until $100 \mathrm{MPa}$ ) on weathered granite soils, which is another type of weak-grained soil. They related the observed difference to the single particle crushing strengths of dry and soaked particles and found that water causes a notable reduction of the first crushing strengths, which are associated with the breaking of corners and asperities, and are responsible for the resulting compression behaviour.

As a part of a broader study on the effect of water on the stress-strain behaviour of calcareous sands, a sand from the Persian Gulf is subjected to a series of one-dimensional compression tests in dry and wet conditions. It is evaluated how much the compressibility and crushability are affected by the water content. The results are compared with those of a reference noncrushable sand in an identical test set-up. It appears that, within the $0 \mathrm{MPa}$ to $8.6 \mathrm{MPa}$ stress region, the one-dimensional compression behaviour of crushable sand is greatly affected by the water whereas the noncrushable sand reacts the same whether it is subjected to dry or wet conditions. Since these stress levels are commonly encountered in geotechnical activities such as pile driving and cone penetration testing, the design and data interpretation for construction sites that contain calcareous sands and are susceptible to dry-wet cycles, should address the effect of water.

\section{MATERIAL DESCRIPTION}

For this study two materials were tested: $\mathrm{S} 2$ is a calcareous sand from the Persian Gulf, with angular grains and a high $\mathrm{CaCO}_{3}$ content in the form of aragonite and calcite. Because of the angular shape of its particles, the brittleness of the mother material and the presence of intraparticle voids, it represents very well a crushable sand. The second sand used is Molsand, a typical silica sand from Belgium that has been tested in many studies and serves here as the referential non-crushable sand. It is composed of subrounded to rounded grains of quartz origin (Van Impe 1981). The granulometric distributions of both sands are given in Figure 1, their physical properties are listed in Table 1 .

\section{TEST DESCRIPTION}

All samples are carefully assembled from weighted sieve fractions to maintain the same grading at the start of every test. As such, the breakage potential (the area above the grain size distribution curve indicated in Figure 1) (Hardin 1985) also remains the same, legitimating the comparison of breakage.

The tests presented here were done at a relative density of $D_{r}=60 \%$ for multiple reasons: it is considered

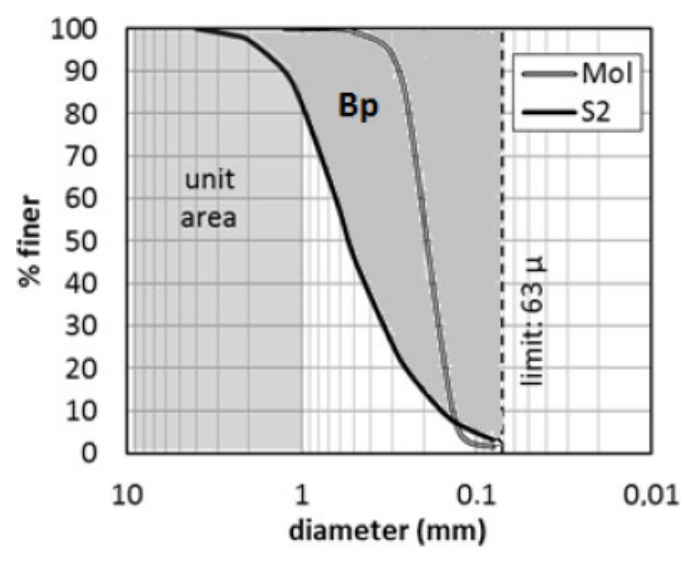

Figure 1. Grain size distributions of S2 and Molsand. The definition of breakage potential (adapted because of the use of ASTM sieves) $B_{p}$ is indicated for S2 sand.

Table 1. Physical properties of tested sands.

\begin{tabular}{lll}
\hline & $\mathrm{S} 2$ & Mol \\
\hline $\mathrm{CU}$ & 3.67 & 0.63 \\
$\mathrm{D}_{50}$ & $0.57 \mathrm{~mm}$ & $0.20 \mathrm{~mm}$ \\
$\mathrm{~B}_{\mathrm{p}}$ & 0.92 & 0.48 \\
$\mathrm{G}_{\mathrm{s}, \text { intact }}$ & $2.82 \mathrm{~g} / \mathrm{cm}^{3}$ & $2.70 \mathrm{~g} / \mathrm{cm}^{3}$ \\
$\mathrm{G}_{\mathrm{s}, \text { powder }}$ & $2.88 \mathrm{~g} / \mathrm{cm}^{3}$ & $2.70 \mathrm{~g} / \mathrm{cm}^{3}$ \\
$\mathrm{CaCO}_{3}$ & $92 \%$ & $0 \%$ \\
$\mathrm{e}_{\min }$ & 0.832 & 0.604 \\
$\mathrm{e}_{\max }$ & 1.382 & 0.912 \\
\hline
\end{tabular}

to be a relevant in-situ value, it provides a stable structure that won't easily collapse upon saturation and it can be reached without crushing by soft sideways hammer blows against the sample holder. To allow for such a densification method, a new oedometer cell is used in this study, consisting of a steel cylinder of $50 \mathrm{~mm}$ internal diameter.

As soon as the dry samples are prepared and set up in the oedometer, the recording of settlements is initiated. Saturation is established and maintained using a set-up comparable to that of the constant head hydraulic conductivity test. A dry sample is flushed with water from the bottom upwards, and finally the water table is kept constant at a level just above the rim of the mould. The saturation process induces small deformations that are recorded at a frequency of $1 \mathrm{~Hz}$. The moment these settlements stabilize the sample is considered to be saturated, and the incremental loading is begun. Starting at a vertical stress of $17 \mathrm{kPa}$, the load is doubled every 24 hours, for 10 days, until a final stress of $8.6 \mathrm{MPa}$ is reached.

When the samples are sieved following the oedometer tests, the difference in grain size distribution is measured using Hardin's relative breakage factor (Hardin 1985), defined as the ratio of total (Figure 7) to potential breakage. 


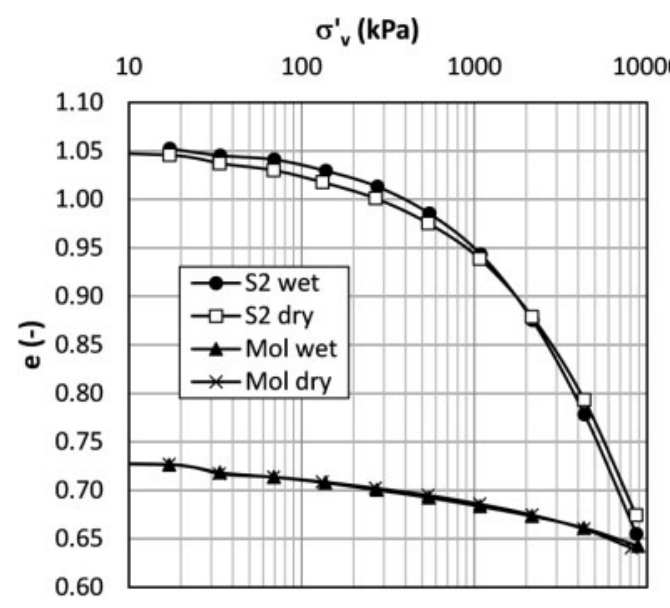

Figure 2. Load-settlement curves from wet and dry oedometer tests on Molsand and S2 sand.

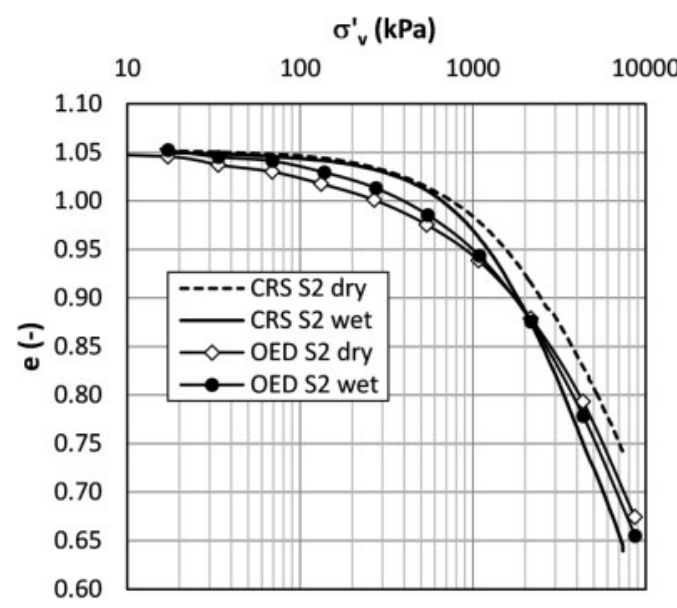

Figure 3. Comparison between incremental oedometer and CRS tests on wet and dry S2 sand.

\section{RESULTS}

Figure 2 shows the void ratio - vertical stress curves of the different sands in wet and dry conditions. For Molsand, the (e, $\left.\log \sigma_{\mathrm{v}}\right)$-curves coincide for the stress levels considered; indeed the normal compression line is not yet reached as the maximum stress that could be obtained in the oedometer apparatus (8.6 MPa) was not high enough to initiate crushing.

For the S2 sand, there is a turning point at around $1 \mathrm{MPa}$. For lower stresses the wet S2 sand underwent less deformation, whereas at higher stresses, it overtook the dry sand in total deformation. The turning point coincides with the yield points of both S2 curves (as determined by the method of Casagrande).

One dimensional compression tests on dry and wet S2 sand were also done at a constant strain rate of $0.033 \mathrm{~mm} / \mathrm{min}$ so a total stress of $7.5 \mathrm{MPa}$ was reached after a few hours only. As can be seen in Figure 3, the

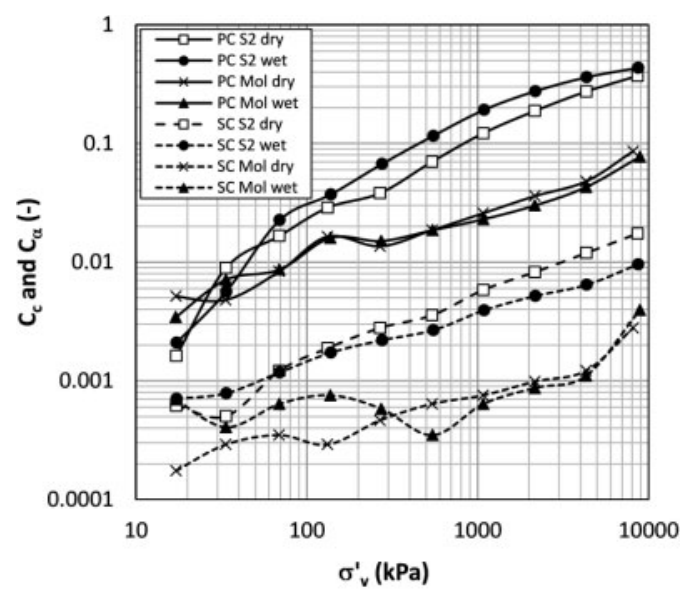

Figure 4. Primary and secondary compression index for wet and dry S2 and Molsand, as a function of vertical stress.

(e, $\log \sigma_{\mathrm{v}}$ )-curve of the wet $\mathrm{S} 2$ sand already yields at $500 \mathrm{kPa}$ in this fast test, coincidently with its deviation from the dry behaviour.

In the study of consolidation, the end of consolidation is determined from oedometer $(\mathrm{e}, \log \mathrm{t})$-curves. For sand, this hydrodynamic period is very short, i.e. compression occurs under drained conditions and grain rearrangement takes place unhindered - as if the sand was dry. The outcome of both dry and wet oedometer tests in this study are therefore interpreted using the definitions of consolidation of saturated soil. Thus, all $(e, \log t)$-curves are separated in a short primary compression (consolidation) phase, followed by a linear, secondary (long-term) compression phase that lasts approximately 24 hours. The characterizing compression indices for each phase, $\mathrm{C}_{\mathrm{c}}$ and $\mathrm{C}_{\alpha}$ can then be compared; they are defined as:

$\frac{C_{c}}{1+e_{0}}=\frac{\Delta \varepsilon_{v}}{\Delta \log \sigma_{v}}$

$\frac{C_{\alpha}}{1+e_{0}}=\frac{\Delta \varepsilon_{v}}{\Delta \log t}$

For the $\left(\mathrm{C}_{\mathrm{c}}, \log \sigma_{\mathrm{v}}\right)$ - and $\left(\Delta \mathrm{e}_{\mathrm{EOP}}, \log \sigma_{\mathrm{v}}\right)$-curves (Figures 4,5 ) obtained from primary compression only, there is a turning point at around $50 \mathrm{kPa}$. It is noted that the accuracy of the calculated $\mathrm{C}_{\mathrm{c}}$ value is subjective to a correct visual determination of the end of primary consolidation $\left(t_{\mathrm{EOP}}, \mathrm{e}_{\mathrm{EOP}}\right)$, therefore the exact turning point is debatable; nevertheless, at lower stresses the wet sand is less compressible than the dry sand. At higher stresses, the wet sand is more compressible than the dry sand. Since deformations after yield are by definition much larger, the higher compressibility of wet sand in the high-stress range leads to a distinct settlement increase. At high stress levels, the $\mathrm{C}_{\mathrm{c}}$-values of wet and dry $\mathrm{S} 2$ seem to approach convergence. 


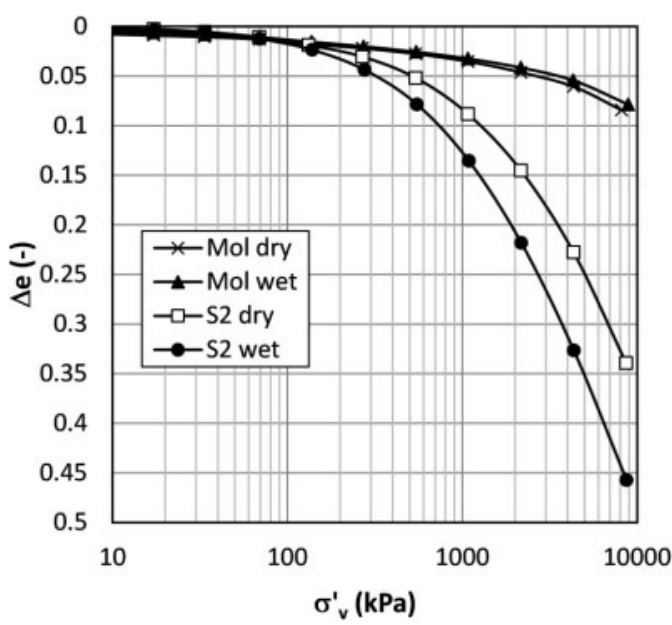

Figure 5. Void ratio changes during primary compression only, as measured in oedometer tests on wet and dry S2 and Molsand.

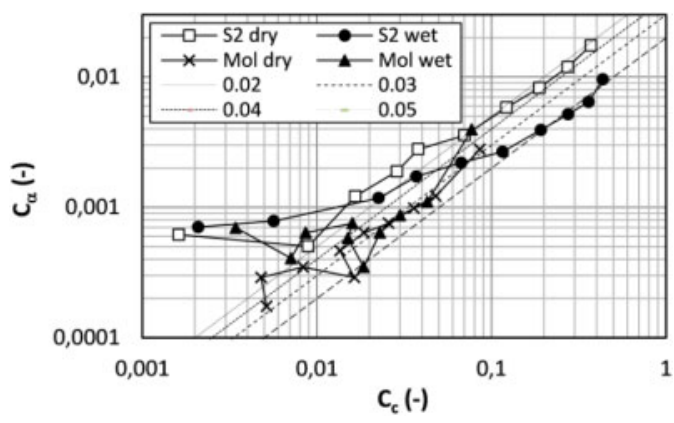

Figure 6. Typical $\mathrm{C}_{\mathrm{c}}-\mathrm{C}_{\alpha}$ relationships for wet and dry Molsand and S2 sand.

On Figure 4 it can be seen that, contrary to the primary compression index $\mathrm{C}_{\mathrm{c}}$, the long-term compression index $\mathrm{C}_{\alpha}$ is slightly higher for dry $\mathrm{S} 2$ sand than for wet $\mathrm{S} 2$ sand. Consequently, the typical ratio $\mathrm{C}_{\alpha} / \mathrm{C}_{\mathrm{c}}$ for wet S2 sand is lower than for dry S2 sand: $\mathrm{C}_{\alpha} / \mathrm{C}_{\mathrm{c}}$ is in the order of $0.03-0.05$ for dry S2, compared to 0.01-0.02 for wet S2 sand (Figure 6). On the other hand, the $\mathrm{C}_{\alpha} / \mathrm{C}_{\mathrm{c}}$ ratio for wet and dry Molsand is similar, albeit not a constant value over the whole stress range, though this is probably because the long term deformations of the stiff Molsand were too small to be accurately measured, leading to some scatter.

Crushability was evaluated from the shift in grain size distribution towards smaller equivalent grain diameters. It is quantified using Hardin's breakage factor, $\mathrm{B}_{\mathrm{r}}$. From these values it appears that the wet $\mathrm{S} 2$ sand underwent more crushing $\left(B_{r}=0.155\right)$ than dry $\mathrm{S} 2$ sand $\left(\mathrm{B}_{\mathrm{r}}=0.131\right)$, whereas it made no difference for Molsand, where crushing remained virtually nil $\left(\mathrm{B}_{\mathrm{r}}=0.005\right)$.

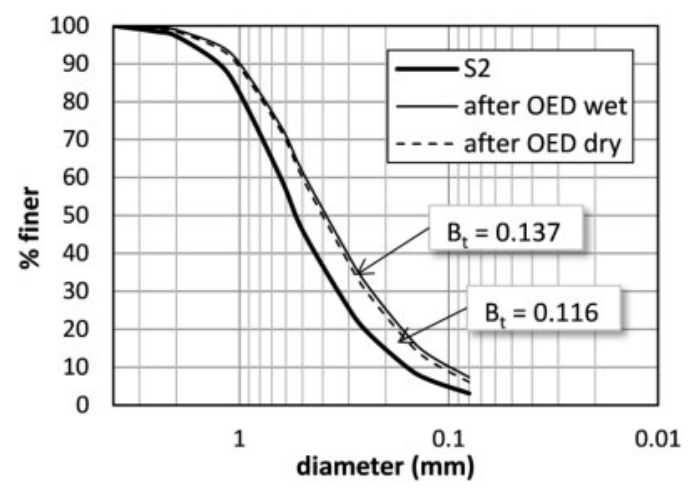

Figure 7. Particle size distributions after oedometer tests on wet and dry S2 sand. The total breakage $B_{t}$ in this study is taken as the area between the original PSD and the PSD after testing, for particles larger than $63 \mu \mathrm{m}$.

\section{INTERPRETATION}

One-dimensional compression curves can be generalised as existing of two phases divided by a yield point (Semple 1988). In the first stage, compression occurs through elastic compression of the soil skeleton and grain rearrangement through particle sliding and rolling (Nauroy \& Le Tirant 1982, Pestana $\&$ Whittle 1995). This initially stiff response of the grain fabric continues until the intergranular stresses exceed the crushing strength of the grain material, then the compressibility increases drastically. This general compression behaviour was indeed observed in the oedometer tests and the CRS test for both wet and dry S2 sand.

As shown in Figures 2-4, the response of wet S2 sand in the first stage of the oedometer compression is slightly stiffer than that of dry S2 sand. Since the response of a freshly deposited sand during the initial loading stages is controlled by the structure and density of the sand (Pestana \& Whittle 1995), the higher stiffness of the wet S2 sand might be due to the sand not being fully saturated at low stress levels, because of an insufficient saturation procedure and/or the complicated shapes of the shells and their semienclosed pores, in which cases local suction prevents the grains from moving and the fabric from adapting to the applied load.

This behaviour of wet calcareous sand was not perceived in the initial compression phase of the more rounded Molsand, and it also did not occur in the fast CRS test, where there was anyway no opportunity for rearrangement of the grains.

The initially stiffer response for dry and wet S2 in CRS tests as compared to oedometer tests, is attributed to columns of stiff grains that withstand vertical deformations. As a consequence, the void ratio of the sample tested in the CRS tests remains higher and the coordination numbers of the particles remain lower, to the point that the intergranular stresses reach the particle crushing strengths at lower 
stress levels, and the compression curve yields earlier and more abruptly. In the oedometer tests the grains settled into a more sustainable and denser packing.

The lower yield stress for wet S2 sand in the CRS test, as compared to the dry test, can be understood from the suction effect when the sand is not yet fully saturated, and increased local inter-particle stresses that promote crushing at lower stresses. Effects of pore water suction obscure the behaviour before yield. After yield, when the stress levels cause the grains to crush, intraparticle voids open up and the saturation of the sample is assured.

The inclination towards convergence of $\mathrm{C}_{\mathrm{c}}$-values of wet and dry S2 at high stresses is similar to the convergence of curves of the same soil at different initial void ratios (Yamamuro et al. 1996) although at some point, when the sand is highly crushed and tightly compacted, the drainage conditions determine how the presence of water will affect the behaviour of crushable sand.

The observed difference in the ratio $\mathrm{C}_{\alpha} / \mathrm{C}_{\mathrm{c}}$ for wet and dry calcareous sands is not in agreement with the usual viewpoint, where the $\mathrm{C}_{\alpha} / \mathrm{C}_{\mathrm{c}}$ value is considered constant for a given soil (Mesri \& Vardhanabhuti 2009) and which holds true for the Molsand. Secondary compression, which is the long-term rearrangement of the grains under a constant stress, furthers the formation of a structure that is able to sustain the constant load, and is an important aging mechanism for granular soils, where the deformation processes that start during consolidation are continued (Mesri \& Vardhanabhuti 2009). From the results presented in this paper, it seems that dry calcareous soils adapt better to loading and form a more stable assembly than when they are wetted. It remains to be investigated what is impeding the wet crushable particles from doing the same.

The breakage analyses from PSD are in accordance with the observed compression curves. As yield did not yet occur during the compression of Molsand, there was no crushing. It is possible that abrasion of the particles did occur, but this does not result in a change in diameter, which is necessary to be captured in a shift of the grading curve (Wils et al. 2013). Wet S2 sand crushed more than dry S2 sand in both the incremental and strain-controlled compression tests. Since the oedometer and CRS tests went on to different vertical stress levels, a comparison of breakage indices could not be made.

\section{CONCLUSION}

The one-dimensional compression behaviour of crushable sand under moderate stress levels is significantly affected by the presence of water. Since these stress levels, soils and water conditions are commonly encountered in geotechnical activities, it is recommended to give the proper consideration to the water-dependency.
The increased deformation for wet calcareous sand occurs mainly during the primary compression phase. In a slow oedometer test, the relatively larger secondary compressive strains of dry calcareous sand caused the total strains to catch up with the excess primary deformation of the wet calcareous sand. On the other hand, in a fast CRS test, the deformations of dry and wet sand don't undergo secondary compression, and the difference in deformation between wet and dry calcareous sand is higher. It is suggested that, at elevated stresses, a slower loading may limit the settlement difference between wet and dry crushable sand.

\section{ACKOWLEDGMENTS}

These tests were done in the Laboratory of Geotechnics at Ghent University.

\section{REFERENCES}

Airey, D.W., Randolph, M.F. \& Hyden, A.M. 1988. The strength and stiffness of two calcareous sands. In: R.J. Jewell \& D.C. Andrews (eds), Engineering for Calcareous Sediments; Proc. Int. Conf., Perth, 15-18 March 1988: 43-50.

Coop, M.R. 1990. The mechanics of uncemented carbonate sands. Géotechnique 40(4): 607-626.

Coop, M.R. \& Lee, I.K. 1993. The behaviour of granular soils at elevated stresses. In: G.T. Houlsby and A.N. Schofield (eds.), Predictive Soil Mechanics; Proc. of Wroth Memorial Symp., Oxford, 27-29 July 1993. London: Thomas Telford 86-198.

Datta, M., Gulhati, S.K. \& Rao, G.V. 1979. Crushing of calcareous sand during shear. Proc. 11th Offshore Tech. Conf., Houston, OTC paper $\mathrm{N}^{\circ} 3525,1459-1467$.

Hagerty, M.M., Hite, D.R, Ullrich, C.R. \& Hagerty D.J. 1993. One-dimensional high-pressure compression of granular media. Journal of Geotechnical Engineering 119(1): $1-18$.

Ham, T.-G., Nakata, Y., Orense, R. \& Hyodo, M. 2010. Influence of water on the compression behavior of decomposed granite soil. J. Geotech. Geoenviron. Eng. 136: 697705.

Hardin, B.O. 1985. Crushing of soil particles. Journal of Geotechnical Engineering 111(10): 1177-1192.

Kwag, J.M., Ochiai, H. \& Yasufuku, N. 1999. Yielding stress characteristics of carbonate sand in relation to individual particle fragmentation strength. In: Al-Shafei (ed.), Engineering for Calcareous Sediments; Proc. of the 2nd Int. Conf., Bahrain, 21-24 February 1999. Rotterdam: Balkema 1: 79-86.

Lade, P.V., Yamamuro, J.A. \& Bopp, P.A. 1996. Significance of particle crushing in granular materials. Journal of Geotechnical Engineering 122(4): 309-316.

Lade, P.V., Yamamuro, J.A. \& Bopp, P.A. 1997. Influence of Time Effects on Instability of Granular Materials. Computers and Geotechnics 20(3/4): 179-193.

Nakata, Y., Kato, Y., Hyodo, M., Hyde, A.F.L. \& Murata, H. $2001 \mathrm{~b}$. One-dimensional compression behaviour of uniformly graded sand related to single particle crushing strength. Soils and Foundations 41(2): 39-51.

Nakata, Y., Hyodo, M., Hyde, A.F.L., Kato, Y. \& Murata, H. 2001a. Microscopic particle crushing of sand subjected 
to high pressure one-dimensional compression. Soils and Foundations 41(1): 69-82.

Nauroy, J.F. \& Le Tirant P. 1982. Comportement des sédiments marins carbonates. Oil \& Gas Science and Technology - Rev. IFP 37(2): 149-155.

Marsal, R.J. 1967. Large scale testing of rockfill materials, Journal of the Soil Mechanics and Foundations Division, 93(SM2): 27-43.

Mesri, G. \& Vardhanabhuti, B. 2009. Compression of Granular Materials. Canadian Geotechnical Journal 46: 369 392.

Miura, N. \& Yamanouchi, T. 1975. Effect of water on the behavior of a quartz-rich sand under high stresses. Soils And Foundations 15(4): P23-34.

Pestana, J.M. \& Whittle, A.J. 1995. Compression model for cohesionless soils. Géotechnique 45(4): 611-631.
Poulos, H.G., Uesugi, M. \& Young, G.S. 1982. Strength and deformation properties of Bass Strait carbonate sands. Geotechnical Engineering 13: 189-211.

Semple, R.M. 1988. The mechanical properties of carbonate soils. In: R.J. Jewell \& M.S. Khorshid (eds.), Engineering for Calcareous Sediments, 807-836.

Van Impe, W.F. 1981. Studie van het vervormingsgedrag van molzand onder cyclisch wisselende belastingen. $P h D$ Thesis, Ghent University.

Wils, L., Van Impe, W.F., Haegeman, W. \& Van Impe, P.O. 2013. Laboratory testing issues related to crushable sands. Proc. 18th Int. Conf. on Soil Mechanics and Geotechnical Engineering, Paris, 2-5 September 2013, 275-278.

Yamamuro, J., Bopp, P., \& Lade, P.V. 1996. One-Dimensional Compression of Sands at High Pressures. J. Geotech. Engrg. 122(2): 147-154. 